\title{
Plasma levels of alpha I-antichymotrypsin and secretory leukocyte proteinase inhibitor in healthy and chronic obstructive pulmonary disease (COPD) subjects with and without severe $\alpha I$-antitrypsin deficiency
}

\author{
Camilla Hollander ${ }^{1}$, Ulla Westin ${ }^{1}$, Anders Wallmark², Eeva Piitulainen ${ }^{2}$, \\ Tomas Sveger ${ }^{3}$ and Sabina M Janciauskiene*2
}

Address: ${ }^{1}$ Departments of Otolaryngology and Head and Neck Surgery, Institution of Clinical Sciences, Lund University, University Hospital Malmö, SE-205 02 Malmö, Sweden, ²Department of Medicine, Institution of Clinical Sciences, Lund University, University Hospital Malmö, SE20502 Malmö, Sweden and ${ }^{3}$ Department of Pediatrics, Institution of Clinical Sciences, Lund University University Hospital Malmö, SE-205 02 Malmö, Sweden

Email: Camilla Hollander - Camilla.Hollander@med.lu.se; Ulla Westin - Ulla.Peterson-Westin@skane.se;

Anders Wallmark - Anders.Wallmark@skane.se; Eeva Piitulainen - Eeva.Piitulainen@skane.se; Tomas Sveger - Tomas.Sveger@skane.se;

Sabina M Janciauskiene* - Sabina.Janciauskiene@med.lu.se

* Corresponding author

Published: 29 January 2007

BMC Pulmonary Medicine 2007, 7:1 doi:10.1 186/1471-2466-7-I

This article is available from: http://www.biomedcentral.com/I47I-2466/7/I

(C) 2007 Hollander et al; licensee BioMed Central Ltd.

This is an Open Access article distributed under the terms of the Creative Commons Attribution License (http://creativecommons.org/licenses/by/2.0), which permits unrestricted use, distribution, and reproduction in any medium, provided the original work is properly cited.
Received: II September 2006

Accepted: 29 January 2007

\begin{abstract}
Background: Individuals with severe $\mathrm{Z} \alpha \mathrm{l}$-antitrypsin (AAT) deficiency have a considerably increased risk of developing chronic obstructive lung disease (COPD). It has been hypothesized that compensatory increases in levels of other protease inhibitors mitigate the effects of this AAT deficiency. We analysed plasma levels of AAT, $\alpha \mathrm{I}$-antichymotrypsin (ACT) and secretory leukocyte protease inhibitor (SLPI) in healthy (asymptomatic) and COPD subjects with and without AAT deficiency.

Methods: Studied groups included: 7I asymptomatic AAT-deficient subjects (ZZ, $n=48$ and SZ, $n=23$, age $31 \pm 0.5$ ) identified during Swedish neonatal screening for AAT deficiency between 1972 and 1974; age-matched controls (MM, $n=57$, age $30.7 \pm 0.6)$; older asymptomatic $Z Z(n=10)$; healthy MM ( $\mathrm{n}=20$, age $53 \pm 9.6)$; and COPD patients $(Z Z, n=10$, age $47.4 \pm 11$ and $M M, n=10$, age $59.4 \pm 6.7$ ). Plasma levels of SLPI, AAT and ACT were analysed using ELISA and immunoelectrophoresis.

Results: No significant difference was found in plasma ACT and SLPI levels between the healthy $M M$ and the $Z Z$ or SZ subjects in the studied groups. Independent of the genetic variant, subjects with COPD $(n=19)$ had elevated plasma levels of SLPI and ACT relative to controls $(n=153)$ $(49.5 \pm 7.2$ vs $40.7 \pm 9.1 \mathrm{ng} / \mathrm{ml}, \mathrm{p}<0.00 \mathrm{l}$ and $0.52 \pm 0.19$ vs $0.40 \pm 0.1 \mathrm{mg} / \mathrm{ml}, \mathrm{p}<0.05$, respectively).

Conclusion: Our findings show that plasma levels of ACT and SLPI are not elevated in subjects with genetic AAT deficiency compared MM controls and do not appear to compensate for the deficiency of plasma AAT.
\end{abstract}




\section{Background}

Serine proteases play key roles in coagulation, fibrinolysis, and in kinin and complement activation. The activities of these enzymes are controlled at least in part by specific serine protease inhibitors, most of which are serpins. The relationship between serine protease and serpin inhibitor levels has been examined extensively, since an imbalance between them is linked to local tissue injury and to many pathologies, including cancer, autoimmune diseases, chronic obstructive lung disease (COPD), inflammation and infectious diseases [1-5].

The serine protease inhibitor found in highest concentration in plasma is $\alpha 1$-antitrypsin (AAT). Severe AAT deficiency in the homozygous $Z$ variant, which differs from the wild type $M$ variant in the substitution of Glu-342 by Lys, was first recognized as a hereditary condition predisposing to COPD on the basis of low plasma levels $(10 \%$ of normal) of AAT [6]. This single amino acid mutation perturbs the folding and tertiary structure of AAT, leading to spontaneous polymerization and cellular retention. Thus, it is a failure in the secretion rather than biosynthesis of AAT that leads to the deficiency [6,7]. AAT is mainly synthesized by liver cells and the $Z$ variant of AAT is retained as inclusion bodies in the endoplasmic reticulum of hepatocytes[8]. These Z-AAT polymers are hypothesized to be cytotoxic and cause liver damage with variable clinical presentation ranging from neonatal cholestasis to liver cirrhosis and hepatocellular carcinoma in adults [911].

Individuals with severe AAT deficiency have at least a 20fold increased risk of developing lung disease, especially if they smoke [12]. AAT is the most important inhibitor of neutrophil elastase and proteinase 3 , and it was suggested that proteases from activated neutrophils, inadequately regulated by AAT, cause destruction of lung tissue [13]. Other serine protease inhibitors, such as $\alpha 1$-antichymotrypsin (ACT), $\alpha 2$-macroglobulin ( $\alpha 2 \mathrm{MG}$ ), antithrombin and antiplasmin, also play important roles in controlling serine protease activity. While these latter inhibitors are produced mainly by the liver and reach tissues by passive diffusion [14], other serine protease inhibitors, such as Secretory Leukocyte Proteinase Inhibitor (SLPI) and elafin/SKALP, are produced locally by airway epithelial cells $[15,16]$. It was proposed that SLPI, as a major antielastase inhibitor of the bronchi, is important for protecting the respiratory epithelium $[17,18]$. In contrast to AAT, SLPI blocks elastin-bound elastase in the alveolar walls, which might also protect against the development of COPD [19].

It has been hypothesized that compensatory increases in other protease inhibitors and/or decreased leukocyte activity may reduce the severity of AAT deficiency by favourably affecting the overall protease/protease-inhibitor balance in AAT-deficient individuals [20-22]. To further test this hypothesis that compensating increases of other protease inhibitor concentrations occur in cases with inherited AAT deficiency, we determined plasma AAT, ACT and SLPI levels in different age groups of healthy and COPD adult subjects with and without AAT deficiency.

\section{Methods \\ Study subjects}

The first study group included 71 asymptomatic, 31 year old, AAT-deficient subjects: ZZ, n $=48,24$ females and 24 males, age $31.1 \pm 0.52$ years and $S Z, n=23,12$ females and 11 males, age $31 \pm 0.58$ years, identified in the Swedish neonatal screening study during 1972-1974 [20-22]. Clinical examination, spirometry, and routine blood tests were performed by a chest physician at the local hospitals. An age-matched control group MM ( $\mathrm{n}=57,33$ females and 24 males, age $31.7 \pm 0.6$ years) was recruited from the general population living in the south of Sweden. No significant differences in lung function $\left(\mathrm{FEV}_{1}\right.$ and $\mathrm{FEV}_{1} /$ FVC\%) was found among the studied subject groups with $\mathrm{ZZ}, \mathrm{SZ}$ and MM variants of AAT.

The second study group consisted of 20 healthy MM AAT adults (11 males and 9 females, aged $53 \pm 9.6$ years), 10 asymptomatic ZZ AAT adults ( 5 males and 5 females, aged $53 \pm 9.6$ years) and 20 COPD patients, among them 10 patients with ZZ AAT ( 5 males and 5 females, aged $47.4 \pm$ 11 years) and 10 patients with MM AAT ( 5 males and 5 females, aged $59.4 \pm 6.7$ years). COPD was diagnosed according to the NHLBI/WHO Workshop guidelines [23]. The ZZ and MM COPD patients had a forced expiratory volume in one second (FEV1) $\leq 80 \%$ of that predicted and a FEV1/Forced vital capacity ratio (FVC) $\leq 70 \%$, while asymptomatic $\mathrm{ZZ}$ individuals had normal lung function. All COPD patients included in the study were in a stable, non-exacerbated phase of the disease. The exclusion criteria were liver diseases, vasculitic or other extra-pulmonary diseases. The control subjects showed no evidence of any disease and had no respiratory symptoms; none of them was on medication and all had MM variant and normal plasma concentration of AAT. The ZZ individuals were recruited from the Swedish AAT Deficiency Register. The MM COPD individuals were outpatients at the Department of Respiratory Medicine, University Hospital, Malmo. The healthy volunteers were recruited from the hospital staff and their relatives. All individuals gave a signed, informed consent to take part in this study, which has been approved by the research ethical committee of Lund University, Sweden. 


\section{Blood sample collection}

Blood was taken by venipuncture, plasma was directly separated by centrifugation and stored at $-20^{\circ} \mathrm{C}$ or $-80^{\circ} \mathrm{C}$ until assayed. AAT-phenotyping was performed by isoelectric focusing at the Department of Clinical Chemistry, University Hospital.

\section{Assay of SLPI}

Secretory leukocyte proteinase inhibitor (SLPI) was analysed using ELISA kits (R\&D Systems Europe Ltd, Abingdon, UK) according to the manufacturer's instructions. Absorbance was measured spectrophotometrically at 450 $\mathrm{nm}$ using a microplate reader (Labsystems). The minimum detectable level of SLPI was $0,0625 \mathrm{ng} / \mathrm{ml}$.

\section{Quantitative analysis of ACT and AAT}

The plasma concentration of ACT and AAT was determined by the rocket immunoelectrophoresis method based on a quantitative estimation of proteins by electrophoresis in 1\% agarose gel containing monospecific antibodies against ACT or AAT at a concentration of $5.5 \mu \mathrm{g}$ per square gel area [23]. The ACT concentration was quantified by counting the height of the rocket-shaped precipitation zone. For the calibration curve a standard plasma Seronorm $^{\mathrm{TM}}$ with a known concentration of ACT and AAT was used.

\section{Statistical analysis}

The statistical package SPSS for Windows (release 11.5, SPSS Inc., Chicago) was used for statistical calculations. Differences in the means were analysed for their statistical significance with the one-way ANOVA combined with a multiple-comparisons procedure (Scheffe multiple range test). The equality of means was analysed for statistical significance with an independent two sample t-test and Pearson correlation analysis. Tests showing $\mathrm{p}<0.05$ were considered to be significant. Data are expressed as mean \pm SD.

\section{Results}

Plasma levels of serine protease inhibitors in 31 year old asymptomatic AAT-deficiency and age and gender matched MM AAT subjects

As expected, plasma levels of AAT in 31 year old subjects were ranked: $\mathrm{MM}>\mathrm{SZ}>\mathrm{ZZ}$ and are significantly different among the groups $[\mathrm{F}(2 / 125)=216, \mathrm{p}<0.001]$ (Table 1$)$. However, we found no significant difference in plasma ACT and SLPI levels between subjects with deficiency of AAT and subjects with wild type AAT (age and gender matched controls)
Plasma levels of serine protease inhibitors in older healthy (asymptomatic) and COPD subjects with and without severe $Z$ AAT deficiency

We found no significant difference in plasma levels of SLPI and ACT between deficiency and normal AAT subjects in the absence of COPD (Table 2A). For the COPD cases (Table 2B), the only difference between normal and AAT deficiency groups is a marginally (within standard deviation) higher plasma ACT level in the cases with MM AAT compared to those with ZZ AAT $[\mathrm{t}(17)=2.5, \mathrm{p}<$ 0.05)].

\section{Plasma levels of serine protease inhibitors in healthy (asymptomatic) and COPD subjects independent of genetic variant of AAT and age}

It is noteworthy that AAT levels were similar in all asymptomatic ZZ AAT cases independent of age $(0.27 \pm 0.05 \mathrm{mg} /$ $\mathrm{ml}, \mathrm{n}=48$, mean age 32 years and $0.2 \pm 0.03 \mathrm{mg} / \mathrm{ml}, \mathrm{n}=$ 10 , mean age 53 years), while ZZ COPD patients had $25 \%$ higher plasma AAT levels compared to asymptomatic ZZ cases, although this was not statistically significant. We also compared levels of ACT and SLPI in healthy/asymptomatic and COPD individuals independent of the genetic variant of AAT and age. As shown in Table 3, levels of both protease inhibitors were found to be elevated in COPD patients relative to healthy subjects (ACT $\mathrm{t}(19.4)=$ $2.8, \mathrm{p}<0.05$ and SLPI $\mathrm{t}(167)=4.2, \mathrm{p}<0.001)$. Previous studies have also demonstrated increased levels of ACT, SLPI and $\alpha 2-M G$ in COPD [24-27].

\section{Discussion}

To contain the potential injurious effects of serine proteases, the anti-proteases developed in a parallel network consisting of "alarm", locally produced such as SLPI and elafin/ESI/SKALP, and "systemic" inhibitors. The latter, such as $\alpha 2-\mathrm{MG}, \mathrm{ACT}$ and AAT $[28,29]$, are synthesized mainly in the liver and can reach the lungs by passive diffusion $[30,31]$. The point mutations in the gene that result in plasma deficiency of AAT or ACT are associated with COPD [32]. However, no polymorphisms have been reported for SLPI or elafin, and therefore, the question remains open as to whether a deficit in either SLPI or elafin contributes to the development of COPD in patients who otherwise have sufficient levels of AAT and ACT. On the other hand it has been suggested that increased plasma levels of other serine protease inhibitors, such as ACT and SLPI, might favourably improve the protease/anti-protease balance in subjects with severe AAT deficiency.

To further evaluated this hypothesis, we analysed plasma levels of AAT, ACT and SLPI and compared in both healthy and COPD adult patients with and without AAT deficiency. We analysed these inhibitors in two different groups of individuals, the first group consisting of 31 year 
Table I: Plasma levels of serine protease inhibitors in 3 I year old asymptomatic AAT-deficiency and age and gender matched wildtype AAT subjects.

\begin{tabular}{lccccc}
\hline AAT-variant & $\mathrm{N}$ & $\mathrm{F} / \mathrm{M}$ & $\begin{array}{c}\text { AAT }(\mathrm{mg} / \mathrm{ml}) \\
\text { Mean } \pm \text { SD }\end{array}$ & $\begin{array}{c}\text { ACT }(\mathrm{mg} / \mathrm{ml}) \\
\text { Mean } \pm \text { SD }\end{array}$ & $\begin{array}{c}\text { SLPI }(\mathrm{ng} / \mathrm{ml}) \\
\text { Mean } \pm \text { SD }\end{array}$ \\
\hline ZZ & 48 & $24 / 24$ & $0.27 \pm 0.05$ & $0.41 \pm 0.11$ & $40.2 \pm 9.6$ \\
SZ & 23 & $12 / 11$ & $0.64 \pm 0.14$ & $0.39 \pm 0.08$ & $40.7 \pm 8.7$ \\
MM & 57 & $33 / 24$ & $1.44 \pm 0.43$ & $0.38 \pm 0.08$ & $41.0 \pm 7.6$ \\
\hline
\end{tabular}

$\mathrm{N}$-number of subjects

$\mathrm{SD}$, standard deviation

old asymptomatic AAT deficiency individuals from the prospective follow-up study [20], and the second consisting of older asymptomatic and COPD subjects with severe AAT deficiency from the Malmö AAT Deficiency Register. Age and gender matched individuals with wild type MM AAT were used for comparison.

Reports published from the prospective follow-up study of ZZ and SZ individuals up to age 26 years, focusing on clinical health, lung and liver function tests and plasma markers of the protease/protease inhibitor balance, have shown that ZZ and SZ subjects had significantly higher plasma concentrations of $\alpha 2-\mathrm{MG}, \mathrm{ACT}$ and antithrombin III [20] at age 8 and 18 compared with MM control subjects. Recent findings at age 26 for ZZ and SZ subjects with normal lung function and only marginal deviations in liver test results showed significantly higher plasma SLPI levels, but not $\alpha 2-\mathrm{MG}$, compared to age matched healthy $M M$ subjects [20]. In contrast, at age 31 , we find in this study that ZZ and SZ individuals have no significant difference in plasma SLPI and ACT levels compared to MM controls. The higher plasma $\alpha 2-\mathrm{MG}$, SLPI and ACT levels reported in AAT deficiency subjects at younger ages were previously attributed to an unidentified compensatory mechanism that protects lung tissue against proteolytic injury under conditions of AAT depletion. Our results show that this differential is not observed at age 31 and older, and raise the question of whether the marginal differences in protease inhibitor levels observed at younger ages between AAT deficient subjects and normal are of clinical importance.

The increased protease inhibitor plasma levels in young AAT deficiency subjects relative to normal subjects could be linked to age rather than to a ZZ or SZ phenotype. For instance, $\alpha 2-M G$ levels in cord blood and in young children have been found to be very high and to fall fairly rapidly from age 15 to 20 years, and to continue to decline gradually until the age of 30 to 40 [33-35]. Similar measurements in another study found concentrations of $\alpha 2$ MG in normals to be high in youth, reach their minimum in middle age, and gradually increase with old age [36]. It has been shown that plasma $\alpha 2$ MG levels in ZZ AAT subjects dropped from $310 \%$ at age 8 years to $215 \%$ at 18 years and to normal $100 \%$ levels at adult age. This pattern tracked that observed in MM AAT control 8-year olds in whom the plasma concentrations of $\alpha 2-\mathrm{MG}$ and $\alpha 2$ antiplasmin were found to be increased up to $252 \%$ and

Table 2: Plasma levels of serine protease inhibitors in older healthy (asymptomatic) and COPD subjects with and without severe $Z$ AAT deficiency.

\begin{tabular}{|c|c|c|c|c|c|c|}
\hline \multicolumn{7}{|c|}{ Healthy (asymptomatic) subjects (A) } \\
\hline AAT-variant & $\mathrm{N}$ & AAT (mg/ml) & $\mathrm{N}$ & ACT (mg/ml) & $\mathrm{N}$ & SLPI (ng/ml) \\
\hline & & Mean* \pm SD & & Mean* \pm SD & & Mean* \pm SD \\
\hline $\mathrm{ZZ}$ & 10 & $0.20 \pm 0.03$ & 10 & $0.40 \pm 0.20$ & 9 & $44.0 \pm 15$ \\
\hline$M M$ & 20 & $1.37 \pm 0.20$ & 15 & $0.37 \pm 0.15$ & 13 & $38.2 \pm 9.9$ \\
\hline \multicolumn{7}{|c|}{ COPD subjects (B) } \\
\hline \multirow[t]{2}{*}{ AAT-variant } & $N$ & AAT $(\mathrm{mg} / \mathrm{ml})$ & $\mathrm{N}$ & ACT $(\mathrm{mg} / \mathrm{ml})$ & $\mathrm{N}$ & $\mathrm{SLPI}(\mathrm{ng} / \mathrm{ml})$ \\
\hline & & Mean* \pm SD & & Mean* \pm SD & & Mean* \pm SD \\
\hline $\mathrm{ZZ}$ & 10 & $0.32 \pm 0.17$ & 10 & $0.42 \pm 0.12$ & 10 & $48.5 \pm 8.4$ \\
\hline MM & 10 & $1.73 \pm 0.22$ & 9 & $0.62 \pm 0.21$ & 9 & $51.1 \pm 6.1$ \\
\hline
\end{tabular}

$\mathrm{N}$-subject number

* geometric mean value

SD, standard deviation 
Table 3: Plasma levels of serine protease inhibitors in asymptomatic and COPD subjects independent of genetic variant of AAT

\begin{tabular}{|c|c|c|c|c|}
\hline Subjects & $\mathrm{N}$ & $\begin{array}{c}\text { ACT }(\mathrm{mg} / \mathrm{ml}) \\
\text { Mean* } \pm \text { SD }\end{array}$ & $\mathrm{N}$ & $\begin{array}{l}\text { SLPI }(\mathrm{ng} / \mathrm{ml}) \\
\text { Mean* } \pm \text { SD }\end{array}$ \\
\hline Healthy & 153 & $0.40 \pm 0.10$ & 153 & $40.7 \pm 9.1$ \\
\hline COPD & 19 & $0.52 \pm 0.19$ & 20 & $49.5 \pm 7.2$ \\
\hline
\end{tabular}

*) geometric mean

SD, standard deviation

$\mathrm{N}$-number of subjects

$125 \%$ of adult levels (100\% corresponding to $2.5 \mathrm{mg} / \mathrm{ml}$ and $70 \mu \mathrm{g} / \mathrm{ml}$, respectively)[20] and to decline to normal at adult age. These data indicate an inherent elevation of $\alpha 2-\mathrm{MG}$ in the young that is not exclusive to the AAT deficient population.

It is also important to point out that, for example, when subjects were 26 years old, but not 18 and 31 years old, SLPI was found to be significantly higher in AAT-deficient subjects than in wild type controls. These inconsistent findings during the follow-up studies suggest that plasma may not be the relevant biological fluid to measure SLPI levels. Alternatively, because SLPI is produced locally in the airways and is regulated by various pro-inflammatory stimuli, its plasma levels when analysed in healthy (asymptomatic) subjects may not reflect the real situation. One can not exclude that under inflammatory conditions the compensatory increase in SLPI and/or other protease inhibitors may reduce the severity of AAT deficiency by favourably affecting the overall protease/protease-inhibitor balance in AAT-deficient individuals.

Our data show small increases in ACT and SLPI, as well as AAT, concentrations in normal MM subjects with COPD relative to well subjects. These differences exceed those for the same parameters for $\mathrm{ZZ}$ subjects with and without COPD and suggest that the COPD disease state could confound conclusions drawn from comparative studies seeking to attribute phenotypes (elevated protease inhibitor levels) to genotypes (ZZ, ZS AAT deficiency).

\section{Conclusion}

We conclude that there is no clear evidence for compensatory up-regulation of protease inhibitors, such as ACT and SLPI, in healthy (asymptomatic) subjects with severe AAT deficiency. Thus, the changes in circulating levels of protease inhibitors and their likely impact on individual susceptibility to lung disease remains to be confirmed through further studies.

\section{Abbreviations}

AAT, alpha-1-antitrypsin; PiZZ, homozygous AAT-deficiency variant; PiMM, wild type AAT variant; ACT, alpha- 1-antichymotrypsin; COPD, chronic obstructive pulmonary disease; $\alpha 2-\mathrm{MG}$, alpha2-macroglobulin; SLPI, Secretory leukocyte proteinase inhibitor; $\mathrm{FEV}_{1}$, forced expiratory volume in 1 second; FVC, forced vital capacity;

\section{Competing interests}

The author(s) declare that they have no competing interests.

\section{Authors' contributions}

$\mathrm{CH}$ carried out the analysis, participated in the interpretation of data and helped to draft the manuscript. EP and TS collected patient material. UW and AW helped with the interpretation of data and the study design. SJ designed the study, carried out the final statistical analysis and wrote the manuscript. All authors have read and approved the final manuscript.

\section{Acknowledgements}

The authors wish to thank Ewa Szemberg Rindahl for sample collection and preparation. This work was supported by grants from Zoega's Foundation, Swedish Medical Research Council and Swedish Heart Lung foundation.

\section{References}

I. Tetley TD: New perspectives on basic mechanisms in lung disease. 6. Proteinase imbalance: its role in lung disease. Thorax 1993, 48:560-565.

2. Decock J, Paridaens R, Cufer T: Proteases and metastasis: clinical relevance nowadays? Curr Opin Oncol 2005, 17:545-550.

3. Schoofs L, Clynen E, Salzet M: Trypsin and chymotrypsin inhibitors in insects and gut leeches. Curr Pharm Des 2002, 8:483-491.

4. Hiemstra PS: Novel roles of protease inhibitors in infection and inflammation. Biochem Soc Trans 2002, 30: I 16-120.

5. Richardson J, Viswanathan K, Lucas.A: Serpins, the vasculature, and viral therapeutics. Front Biosci 2006, Jan I: I042-1056.

6. Crystal RG: The alpha I-antitrypsin gene and its deficiency states. Trends Genet 1989, 5:41 I-417.

7. Luisetti M, Seersholm N: Alphal-antitrypsin deficiency. I: epidemiology of alphal-antitrypsin deficiency. Thorax 2004, 59:164-169.

8. Sandford Al, Silverman EK: Chronic obstructive pulmonary disease. I: Susceptibility factors for COPD the genotype-environment interaction. Thorax 2002, 57:736-74I.

9. Carrell RW, Lomas DA: Alpha I-antitrypsin deficiency--a model for conformational diseases. $N$ Engl J Med 2002, 346:45-53.

10. Brantly ML: Alphal-antitrypsin genotypes and phenotypes. In: Crystal RG, ed. Alphal-antitrypsin deficiency. New York: Marcel Dekker 1996:45 -459.

II. Carrell RW, Lomas DA, Sidhar S, Foreman R: Alpha I-antitrypsin deficiency. A conformational disease. Chest 1996, I I 0:243S-247S.

12. Ranes J, Stoller JK: A review of alpha-I antitrypsin deficiency. Semin Respir Crit Care Med 2005, 26:154-166.

13. Taggart CC, Greene CM, Carroll TP, O'Neill SJ, McElvaney NG: Elastolytic proteases: inflammation resolution and dysregulation in chronic infective lung disease. Am J Respir Crit Care Med 2005, 171:1070-1076.

14. Kalsheker N, Morley S, Morgan K: Gene regulation of the serine proteinase inhibitors alpha I-antitrypsin and alphal-antichymotrypsin. Biochem Soc Trans 2002, 30:93-98.

15. Sallenave JM, Shulmann J, Crossley J, Jordana M, Gauldie J: Regulation of secretory leukocyte proteinase inhibitor (SLPI) and elastase-specific inhibitor (ESI/elafin) in human airway epithelial cells by cytokines and neutrophilic enzymes. Am J Respir Cell Mol Biol I994, I I:733-74I.

16. Sallenave JM, Si-Ta har M, Cox G, Chignard M, Gauldie J: Secretory leukocyte proteinase inhibitor is a major leukocyte elastase inhibitor in human neutrophils. J Leukoc Biol 1997, 61:695-702. 
17. Ohlsson $\mathrm{K}$, Tegner $\mathrm{H}$ : Inhibition of elastase from granulocytes by the low molecular weight bronchial protease inhibitor. Scand J Clin Lab Invest 1976, 36:437-445.

18. Tegner H: Quantitation of human granulocyte protease inhibitors in non-purulent bronchial lavage fluids. Acta Otolaryngol 1978, 85:282-289.

19. Bruch M, Bieth JG: Influence of elastin on the inhibition of leucocyte elastase by alpha I-proteinase inhibitor and bronchial inhibitor. Potent inhibition of elastin-bound elastase by bronchial inhibitor. Biochem J 1986, 238:269-273.

20. Sveger T: Plasma protease inhibitors in alpha I-antitrypsindeficient children. Pediatr Res 1985, 19:834-835.

21. Sveger T, Ohlsson K, Piitulainen E: Adolescents with alpha I-antitrypsin deficiency have high alpha2-macroglobulin and low neutrophil lipocalin and elastase levels in plasma. Pediatr Res 1998, 44:939-94I.

22. Piitulainen E, Carlson J, Ohlsson K, Sveger T: \{alpha\} I-Antitrypsin Deficiency in 26-Year-Old Subjects: Lung, Liver, and Protease/Protease Inhibitor Studies. Chest 2005, I 28:2076-208I.

23. Laurell $C B$ : Quantitative estimation of proteins by electrophoresis in agarose gel containing antibodies. Anal Biochem 1966, I 5:45-52.

24. Crooks SW, Bayley DL, Hill SL, Stockley RA: Bronchial inflammation in acute bacterial exacerbations of chronic bronchitis: the role of leukotriene B4. Eur Respir J 2000, I 5:274-280.

25. Travis J: Structure, function, and control of neutrophil proteinases. Am J Med 1988, 84:37-42.

26. Gompertz S, Bayley DL, Hill SL, Stockley RA: Relationship between airway inflammation and the frequency of exacerbations in patients with smoking related COPD. Thorax 200I, 56:36-4I.

27. Reid PT, Sallenave JM: Neutrophil-derived elastases and their inhibitors: potential role in the pathogenesis of lung disease. Curr Opin Investig Drugs 200I, 2:59-67.

28. Guillen MI, Gomez-Lechon MJ, Nakamura T, Castell JV: The hepatocyte growth factor regulates the synthesis of acute-phase proteins in human hepatocytes: divergent effect on interleukin-6-stimulated genes. Hepatology 1996, 23: I 345-I352.

29. Abbinante-Nissen JM, Simpson LG, Leikauf GD: Neutrophil elastase increases secretory leukocyte protease inhibitor transcript levels in airway epithelial cells. Am J Physiol 1993, 265(3 Pt I):L286-292.

30. Vignola AM, Bonanno A, Mirabella A, Riccobono L, Mirabella F, Profita $M$, Bellia V, Bousquet J, Bonsignore G: Increased levels of elastase and alphal-antitrypsin in sputum of asthmatic patients. Am J Respir Crit Care Med I998, I 57:505-5I I.

31. Morrison HM, Kramps JA, Burnett D, Stockley RA: Lung lavage fluid from patients with alpha I-proteinase inhibitor deficiency or chronic obstructive bronchitis: anti-elastase function and cell profile. Clin Sci (Lond) 1987, 72:373-38I.

32. Poller W, Faber JP, Weidinger S, Tief K, Scholz S, Fischer M, Olek K, Kirchgesser M, Heidtmann HH: A leucine-to-proline substitution causes a defective alpha I-antichymotrypsin allele associated with familial obstructive lung disease. Genomics 1993 , I 7:740-743.

33. Ganrot PO: Variation of the alpha 2-macroglobulin homologue with age in some mammals. Scand J Clin Lab Invest 1968, 2I:177-181.

34. Housley J: Alpha-2-macroglobulin levels in disease in man. J Clin Pathol 1968, 2 I:27-31.

35. James K, Johnson G, Fudenberg $\mathrm{HH}$ : The quantitative Estimation of 2-Macroglobulin in Normal, Pathological and Cord Sera. Clin Chim Acta 1966, I 4:207-2I4.

36. Tunstall AM, Merriman JM, Milne I, James K: Normal and pathological serum levels of alpha2-macroglobulins in men and mice. J Clin Pathol 1975, 28:133-139.

\section{Pre-publication history}

The pre-publication history for this paper can be accessed here:

http://www.biomedcentral.com/1471-2466/7/1/prepub
Publish with Biomed Central and every scientist can read your work free of charge

"BioMed Central will be the most significant development for disseminating the results of biomedical research in our lifetime. "

Sir Paul Nurse, Cancer Research UK

Your research papers will be:

- available free of charge to the entire biomedical community

- peer reviewed and published immediately upon acceptance

- cited in PubMed and archived on PubMed Central

- yours - you keep the copyright
BioMedcentral 